\title{
New Approach to Suppress Mutual Coupling Between Longitudinal-Slotted Arrays Based on SIW Antenna Loaded with Metal-Fences Working on VHF/UHF Frequency-Bands: Study, Investigation, and Principle
}

\author{
Mohammad Alibakhshikenari ${ }^{1 *}$, Bal S. Virdee ${ }^{2}$, Chan H. See ${ }^{4}$, Raed Abd-Alhameed ${ }^{5}$, Francisco Falcone ${ }^{6}$, \\ and Ernesto Limiti ${ }^{1}$ \\ ${ }^{1}$ Electronics Engineering Department, University of Rome "Tor Vergata", Via del politecnico 00133, Rome, ITALY \\ ${ }^{2}$ London Metropolitan University, Center for Communications Technology, School of Computing \& Digital Media, \\ London N7 8DB, UK
}

${ }^{3}$ School of Engineering Department, University of Bolton, Deane Road, Bolton, BL3 5AB, UK

${ }^{4}$ School of Electrical Engineering \& Computer Science, University of Bradford, UK

${ }^{5}$ Electric and Electronic Engineering Department, Universidad Pública de Navarra, SPAIN

*alibakhshikenari@ing.uniroma2.it

\begin{abstract}
In this work it is demonstrated that substrate integrated waveguide longitudinal slotted array antenna (SIWLSAA) which is loaded with metal fences exhibits highisolation across VHF/UHF bands. A reference SIWLSAA used for comparison purpose comprises of $3 \times 6$ slotted arrays constructed on the top and bottom sides of the FR-4 lossy substrate has maximum isolation of $-63 \mathrm{~dB}$ between its radiation slots. Improvement in isolation is demonstrated using a simple new technique based on inserting a metal fence between each row of slot arrays. The resulting isolation is shown to be is better than $-83 \mathrm{~dB}$ across $200 \mathrm{MHz}$ to $1.0 \mathrm{GHz}$ with gain greater than $1.5 \mathrm{dBi}$, and side-lobe level less than $40 \mathrm{~dB}$. The proposed SIWLSAA is compact and has dimensions of $40 \times 10 \times 5 \mathrm{~mm}^{3} \quad\left(0.026 \lambda_{0} \times 0.006 \lambda_{0} \times 0.002 \lambda_{0}\right)$ where $\lambda_{0}$ is $200 \mathrm{MHz}$. The proposed structure should find application in multiple-input multiple-output (MIMO) and radar systems.
\end{abstract}

Keywords- Substrate Integrated Waveguide (SIW), slotted array antenna, reduction mutual coupling, metal fences, isolation, multiple output multiple input (MIMO) systems.

\section{INTRODUCTION}

Slotted waveguide antenna arrays (SWAA) are becoming highly attractive components for communications and radar systems because they are highly power efficient, have low cross-polarisation and allow accurate control of the radiation patterns [1-2]. Extension on the work on SWAA has resulted in the development of waveguide longitudinal slot array antennas that can be accurately synthesised using Elliott's design procedure [3-6]. The design of such slot array antennas considers mutual coupling in the determination of slot parameters for a desired aperture distribution and input matching.

Investigation on SWAA has evolved and employ planar guide-wave structures referred to as substrate integrated waveguide (SIW) [7-11], post-wall waveguide [12-14] or laminated waveguide [15]. Guided-wave characteristics of the SIW are essentially like those of a metallic waveguide, and have attractive features including economic manufacture at low-cost with conventional microwave integrated circuit (MIC) technique, low profile, compact size and easy integration with other planar circuits. Unfortunately, SIW-based longitudinal slot array antennas are unsuitable for high performance applications because of unacceptable side-lobe levels (SLLs) [9]. Typically, substrate integrated waveguide longitudinal slot array antennas (SIWLAA) can only achieve -30 dB SLL using highly complex design [16].

In this paper, a new method is proposed to increase the isolation between radiation slots that involves inserting metal fences between longitudinal slot arrays of the substrate integrated waveguide. With this technique it is shown an improvement in mutual coupling suppression between the radiation slots improved by around $30 \mathrm{~dB}$ over the frequency range $0.2-1.0 \mathrm{GHz}$, and the minimum gain is more than $1.5 \mathrm{dBi}$ and side-lobe level is better than $-40 \mathrm{~dB}$. The proposed technique is simple to implement and should enable SIWLSAA for application in MIMO and radar systems.

\section{SUBSTRATE INTEGRATED WAVEGUIDE LONGITUDINAL SLOTTED ARRAY ANTENNA}

A reference longitudinal slotted array antenna, shown in Fig. 1, was fabricated on the substrate integrated waveguide. The antenna was constructed using $3 \times 6$ slotted arrays implemented on the top and bottom sides of the SIW. Unlike conventional designs the reference SIW has no via-holes which would otherwise increase manufacturing complexity. Reflection coefficient $\left(\mathrm{S}_{11}\right)$ and transmission coefficient $\left(\mathrm{S}_{12}\right)$ of SIWLSAA using EM fullwave simulations tool, i.e. CST Microwave Studio and HFSS, are plotted in Fig. 2. These plots show the antenna operates in parts of VHF and UHF frequency bands from around $200 \mathrm{MHz}$ to $1.0 \mathrm{GHz}$ (for $\left|\mathrm{S}_{11}\right| \leq 10 \mathrm{~dB}$ ). The maximum and minimum isolation of $-63 \mathrm{~dB}$ and $-60 \mathrm{~dB}$ are 
at $200 \mathrm{MHz}$ and $1 \mathrm{GHz}$, respectively. The antenna resonates at $440 \mathrm{MHz}$ with impedance matching of $-64 \mathrm{~dB}$.

Metal fences have been inserted between the slots to suppress the mutual coupling between the radiation slots, as shown in Fig. 1. The results in Fig. 2 show the minimum mutual coupling suppression is improved by $\sim 20 \mathrm{~dB}$, and maximum suppression by $\sim 40 \mathrm{~dB}$. These results are summarized in Table. I.

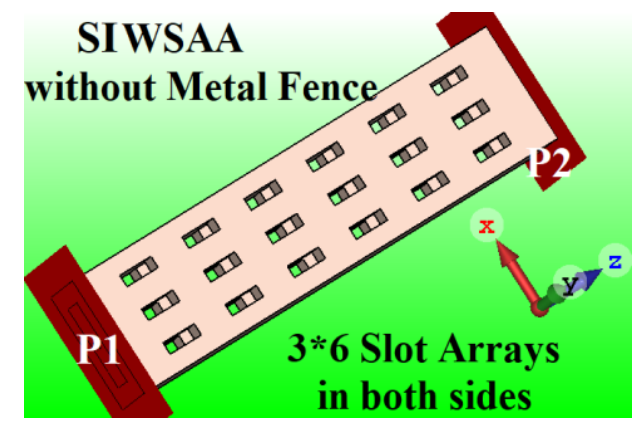

(a) Reference SIWSAA without metal fences as isolator

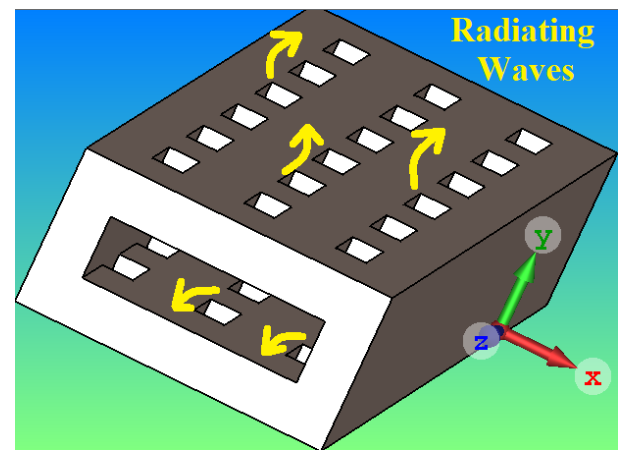

(b) Reference SIWSAA without metal fences as isolator

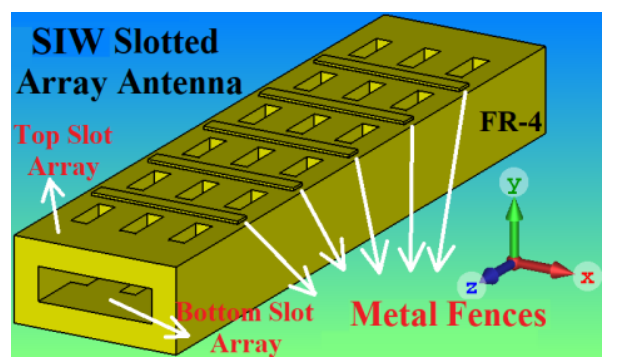

(c) Proposed SIWSAA with metal fences as isolator

Fig. 1. Reference and proposed substrate integrated waveguide slotted array antennas (SIWSAAs)

The results presented in Table I show that with the metal fences the average reduction in mutual coupling between the radiation slots is $\sim 30 \mathrm{~dB}$ over $0.2-1 \mathrm{GHz}$. There is negligible affecting on the frequency bandwidth compared to the reference SIWSAA.

Input impedances $(\Omega)$ and admittances $(1 / \Omega)$ of the proposed substrate integrated waveguide longitudinal slot array antenna with application of the metal fences is shown in Fig. 3. The results were obtained using CST Microwave Studio and HFSS tools. There is excellent agreement between two EM full-wave simulators.

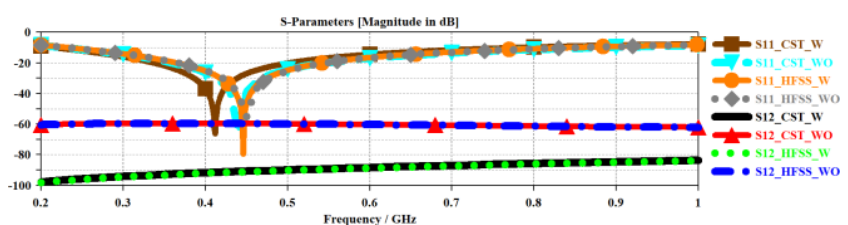

(a)

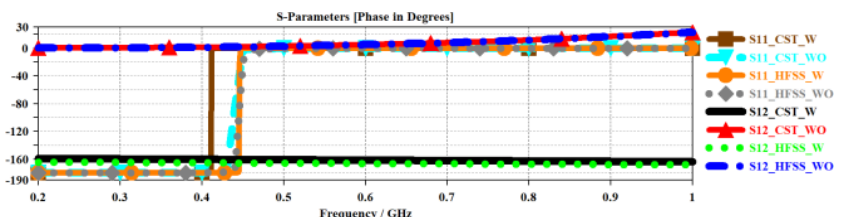

(b)

Fig. 2. S-parameter performances $\left(S_{11}\right.$ and $\left.S_{12}\right)$ of the reference and proposed SIWSAA.

TABLE I. S-PARAMETERS SPECIFICATIONS

\begin{tabular}{|c|c|c|c|}
\hline \multicolumn{4}{|c|}{ For $\left|\mathrm{S}_{11}\right| \leq-10 \mathrm{~dB}: 0.2-1.0 \mathrm{GHz}, \Delta \mathrm{f}=800 \mathrm{MHz}, \mathrm{FBW}=133.3 \%$} \\
\hline $\mathrm{S}_{12}$ & Min. & Max. & Ave. \\
\hline Reference SIWSAA & $-60 \mathrm{~dB}$ & $-63 \mathrm{~dB}$ & $-61.5 \mathrm{~dB}$ \\
\hline Proposed SIWSAA & $-83 \mathrm{~dB}$ & $-98 \mathrm{~dB}$ & $-91 \mathrm{~dB}$ \\
\hline Suppression & $\sim 20 \mathrm{~dB}$ & $\sim 40 \mathrm{~dB}$ & $\sim 30 \mathrm{~dB}$ \\
\hline
\end{tabular}
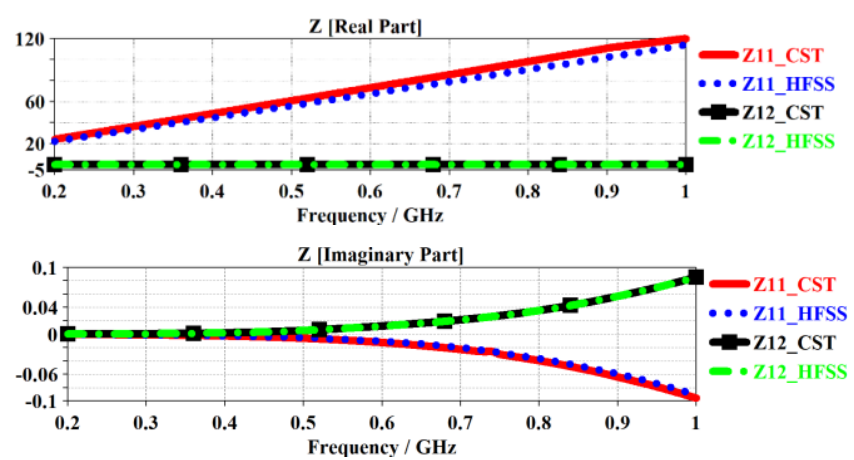

(a) Input impedances $(\Omega)$

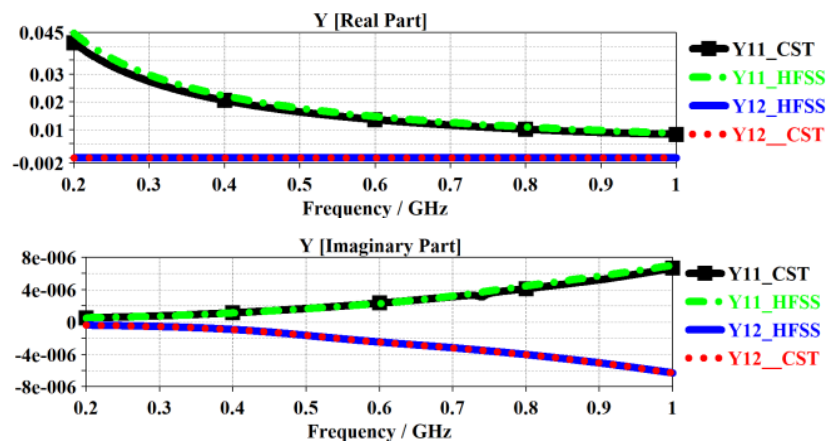

(b) Input admittances $(1 / \Omega)$

Fig. 3. Input impedances $(\Omega)$ and admittances $(1 / \Omega)$ of the proposed substrate integrated waveguide slotted array antenna with metallic fences.

The 2-D and 3-D radiation characteristics of the proposed SIW slot array antenna is plotted in Figs. 4-6. Fig. 4 , shows the 2-D gain plots at two operating frequencies of $500 \mathrm{MHz}$ and $1.0 \mathrm{GHz}$. The gain is greater than $1.7 \mathrm{dBi}$. The maximum gain as a function of frequency is shown in Fig. 5. 

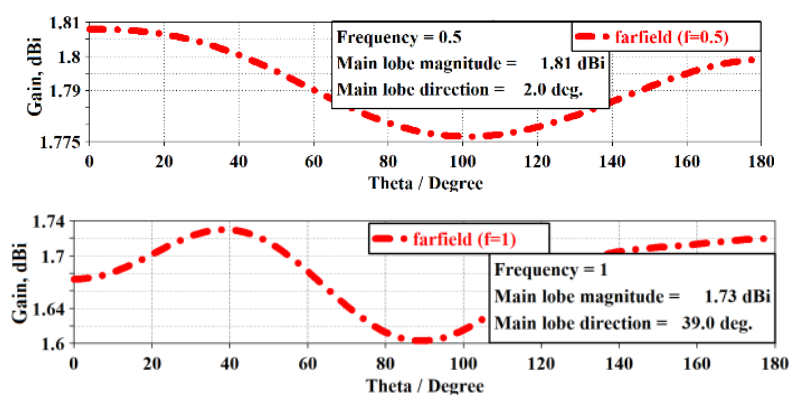

(a) 2-dimentional

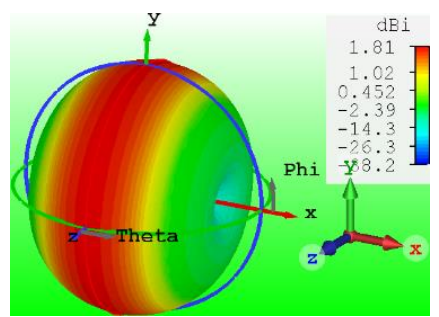

@ $0.5 \mathrm{GHz}$

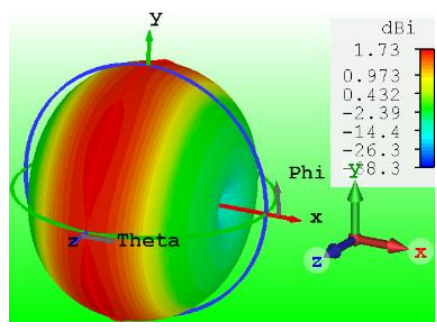

@ $1 \mathrm{GHz}$

(b) 3-dimentional

Fig. 4. Radiation patterns at operating frequencies of 0.5 and $1.0 \mathrm{GHz}$.

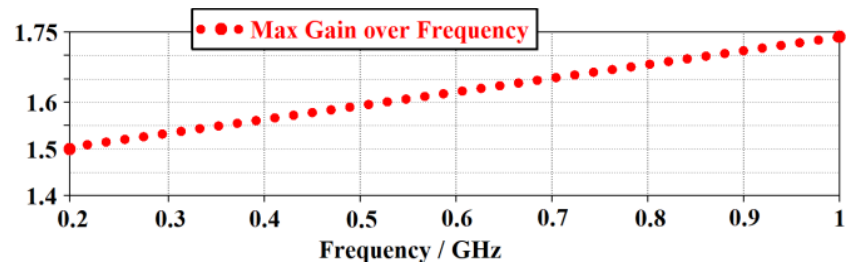

Fig. 5. Maximum gain plot versus frequency.

The radiation patterns of the reference and proposed SIWLSAA with no and with metal-fences in the E- and $\mathrm{H}$ planes at $0.5 \mathrm{GHz}$ and $1 \mathrm{GHz}$ are plotted in Fig. 6. These results show that after implementing the metal-fences the radiation patterns are virtually unaffected. The side-lobe level obtained is $-40 \mathrm{~dB}$ which is significantly better than that reported in literature.

The above results confirm the proposed substrate integrated waveguide longitudinal slotted array antenna provides high isolation between adjacent radiation slots. The technique is very easy to implement and is a low-cost solution.

\section{CONCLUSION}

Metal fences located between longitudinal slot arrays of the substrate integrated waveguide is shown to significantly enhance isolation between the radiating slots. The results confirm the proposed technique has negligible effect on the antennas operational bandwidth and radiation characteristics. Compared to a reference SIWLSAA the proposed technique provides isolation improvement on average of around $30 \mathrm{~dB}$. The technique is simple to implement and should applicable for MIMO and radar systems.
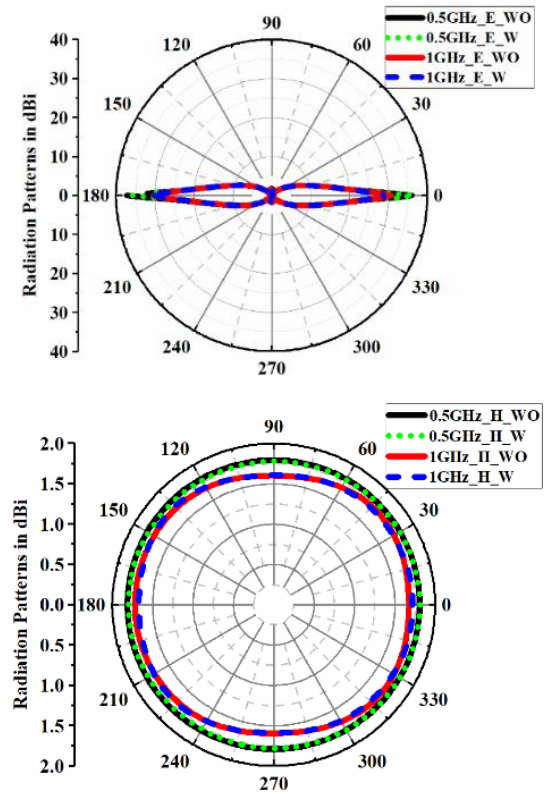

Fig. 6. Radiation patterns of the reference and proposed substrate integrated waveguide longitudinal slotted array antenna without (WO) and with (W) metal fences in E- and $\mathrm{H}$ - planes at 0.5 and $1 \mathrm{GHz}$.

\section{REFERENCES}

[1] R. C. Hansen, Phased Array Antennas. New York: Wiley, 1998

[2] J. L. Volakis, Ed., Antenna Engineering Handbook, 4th ed. McGrawHill Professional, 2009.

[3] STERN G.T., ELLIOTT R.S.: 'Resonant length of longitudinal slots and validity of circuit representation: Theory and experiment', IEEE Trans. Antennas Propag., 1985, 33, (11), pp. 1264-1271.

[4] ELLIOTT R.S.: 'An improved design procedure for small arrays of shunt slots', IEEE Trans. Antennas Propag., 1983, 31, (1), pp. 48-53.

[5] ELLIOTT R.S., O'LOUGHLIN W.R.: 'The design of slot arrays including internal mutual coupling', IEEE Trans. Antennas Propag., 1986, 34, (9), pp. 1149-1154.

[6] ELLIOTT R.S.: 'Antenna Theory and Design' (John Wiley \& Sons Inc., 2003, revised edition).

[7] DESLANDES D., WU K.: 'Integrated microstrip and rectangular waveguide in planar form', IEEE Microw. Wirel. Compon. Lett., 2001, $11,(2)$, pp. 68-70.

[8] DESLANDES D., WU K.: 'Accurate modeling, wave mechanisms, and design considerations of a substrate integrated waveguide', IEEE Trans. Microw. Theory Tech., 2006, 54, (6), pp. 2516-2526.

[9] YAN L., HONG W., HUA G., CHEN J., WU K., CUI T.J.: 'Simulation and experiment on SIW slot array antennas', IEEE Microw. Wirel. Compon. Lett., 2004, 14, (9), pp. 446-448.

[10] HONG W., XU J.F., LAI Q.H., CHEN P.: 'Design and implementation of low sidelobe slot array antennas with full and half mode substrate integrated waveguide technology'. European Microwave Conf., Munich, Germany, October 2007, pp. 428-429.

[11] FARRALL A.J., YOUNG P.R.: 'Integrated waveguide slot antennas', IEE Electron. Lett., 2004, 40, (16), pp. 974-975.

[12] HIROKAWA J., ANDO M.: 'Single-layer feed waveguide consisting of posts for plane TEM wave excitation in parallel plates', IEEE Trans. Antennas Propag., 1998, 46, (5), pp. 625-630.

[13] HIROKAWA J., ANDO M.: 'Sidelobe suppression in 76- GHz postwall waveguide-fed parallel-plate slot arrays', IEEE Trans. Antennas Propag., 2000, 48, (11), pp. 1727-1732. 
[14] SEHYUN P., OKAJIMA Y., HIROKAWA J., ANDO M.: 'A slotted post-wall waveguide array with interdigital structure for $45^{\circ}$ linear and dual polarization', IEEE Trans. Antennas Propag., 2005, 53, (9), pp. 2865-2871.

[15] UCHIMURA H., TAKENOSHITA T., FUJII M.: 'Development of a laminated waveguide', IEEE Trans. Microw. Theory Tech., 1998, 46, (12), pp. 2438-2443.
[16] J.F. Xu, W. Hong, P. Chen, and K. Wu, "Design and implementation of low sidelobe substrate integrated waveguide longitudinal slot array antennas", IET Microw. Antennas Propag., 2009, Vol. 3, Iss. 5, pp. 790 797. 